\title{
ENTRE MIASMAS E O ANOPHELES: UMA BREVE HISTÓRIA DA MALÁRIA NO ALVORECER DA REPÚBLICA EM MANAUS (1898-1904)
}

\author{
Márcio de Carvalho e Silva ${ }^{1}$ \\ Keith Valéria de Oliveira Barbosa ${ }^{2}$
}

\begin{abstract}
RESUMO
Os primeiros anos de República em Manaus foram movimentados devido às alterações significativas na paisagem da cidade, como a construção e o nivelamento de ruas e o aterro de igarapés. Esses acontecimentos foram propiciados graças ao acúmulo de capital advindo da comercialização do látex, a ponto de a cidade ficar conhecida como a "Paris dos Trópicos", dada o cosmopolitismo que a cidade assumira com a economia da borracha. Ao mesmo tempo em que se expandiu enquanto cidade, Manaus também assistiu a expansão de doenças como a malária, esta que protagonizou sucessivas epidemias no período da Belle Époque. No presente artigo iremos abordar como a doença ganhou uma visibilidade diferenciada em relação à época provincial, destacando-se nos relatórios de autoridades sanitárias e dos governantes no alvorecer da República em Manaus. Para tanto utilizaremos a técnica da análise de discursos de modo a verificar as mudanças e permanências no entendimento sobre a doença entre 1898 e 1904. Ao mesmo tempo, iremos verificar como o recrudescimento da doença na cidade traz, à reboque, novos embates entre os médicos amazonenses em relação à etiologia e à transmissão da moléstia, isto é, a partir da ideia do mosquito enquanto vetor nos primeiros anos do século XX.
\end{abstract}

Palavras-chave: Manaus. História da Malária. República. Mosquito.

\section{BETWEEN MIASMAS AND ANOPHELES: A BRIEF HISTORY OF MALARIA AT THE DAWN OF THE REPUBLIC IN MANAUS (1898-1904)}

\begin{abstract}
The first years of the Republic in Manaus were busy due to significant changes in the city's landscape, such as the construction and levelling of streets and the embankment of creeks. These events were propitiated thanks to the accumulation of capital from the latex trade, to the point where the city became known as the "Paris of the Tropics", given the cosmopolitanism that the city assumed with the rubber economy. At the same time as it expanded as a city, Manaus also saw the expansion of diseases such as malaria, which led to successive epidemics during the Belle Époque. In this article we will address how the disease gained a different visibility in relation to the provincial period, highlighting the reports of health authorities and rulers at the dawn of the Republic in Manaus. For that we will use the technique of discourse analysis in order to verify the changes and permanences in the understanding about the disease between 1898 and 1904. At the same time, we will verify how the recrudescence of the disease in the city brings, in tow, new clashes between Amazonian physicians in relation to the etiology and transmission of the disease, that is, from the idea of the mosquito as a vector in the early years of the twentieth century.
\end{abstract}

Keywords: Manaus. History of Malaria. Republic. Mosquito.

\footnotetext{
${ }^{1}$ Mestrando do Programa de Pós-Graduação em História da Universidade Federal do Amazonas (PPGH-UFAM). Professor-titular na Secretária de Educação do Estado do Amazonas (SEDUC). E-mail: marcio.carvalho.silva@seducam.pro.br.

${ }^{2}$ Professora do Curso de História da Universidade Federal do Amazonas e do Programa de Pós-Graduação em História (PPGH-UFAM). Bacharel e Licenciada em História pela Universidade Federal do Rio de Janeiro (2008). Mestre em História pela Universidade Federal Rural do Rio de Janeiro (2010). Doutora em História das Ciências e da Saúde pela Fundação Oswaldo Cruz- Fiocruz (2014).
} 
Data de submissão: 24.04 .2021

Data de aprovação: 16.05 .2021

\section{INTRODUÇÃOO}

O presente artigo trata da história da malária nos primeiros anos da República de Manaus. Nesse período a cidade passava por aquilo que se conheceu como Belle Époque ${ }^{3}$, cenário em que seu espaço urbano começou a ser transformado atendendo os anseios das elites e dos governantes locais. Nesse momento, buscou-se atender a um projeto de modernização do espaço urbano seguindo os moldes europeus com o aterramento de igarapés, a construção de longas avenidas e a instalação do primeiro sistema de esgoto na cidade. Essas transformações foram financiadas pela economia da borracha. No entanto, a pobreza e a miséria vivenciada por grande parte da população da cidade evidenciava as contradições desse período (DIAS, 1999). Ao mesmo tempo em que a paisagem urbana se modificava, encarava-se também velhos problemas, como as epidemias, sobretudo de febre amarela e malária. No instante em que se efetuam as reformas urbanas, a malária tornou-se um problema recorrente na cidade, passando a ser objeto de preocupação de médicos e autoridades locais.

Nesse sentido, buscamos examinar a história da malária nos anos iniciais da República. Para tanto se fez necessário, inicialmente, descrever como a doença era entendida na Província do Amazonas, identificar os agentes que discursavam sobre ela nos primeiros anos da República e, por fim, verificar os embates entre os médicos-sanitaristas em torno da teoria do mosquitovetor.

Durante a época provinciana, as categorias que balizaram a doença se pautavam prioritariamente no termo "febres". Sendo assim, era muito comum haver denominações anexas como febres palustres ou febre palustre para a malária. Essa interpretação se devia naquele momento às influências da teoria dos miasmas no saber médico amazonense. Segundo Cybele Costa (2008), a teoria miasmática encontrou vazão na Província do Amazonas devido em parte às características do meio ambiente amazônico, como o clima quente e úmido e as ações humanas por conta da caça de peixes com timbó, que liberava veneno nos rios e matava os peixes.

Dessa forma, haveria então a liberação de uma matéria pútrida que viajava pela água e pelo ar e seu contato com o corpo humano provocava as febres. Outro ponto se devia à possibilidade das febres serem causadas pelas alterações no temperamento e na constituição física de um indivíduo, que poderiam ocasionalmente desencadear um estado mórbido. Assim, a malária era entendida naquele momento com base nas causas predisponentes, um dos elementos que ajudava a balizar o paradigma miasmático no saber médico no século XIX.

Os reflexos da teoria miasmática no saber médico amazônico acabaram por ultrapassar o século XIX e adentraram o século XX. Observamos isso quando tivemos contato com os relatórios da Junta de Higiene de Manaus. Segundo o Inspetor de Higiene do Estado, Dr. Henrique Alvares Pereira, em 1897:

Examinnando os mapas verifica-se que o impaludismo em suas múltiplas
manifestações foi a que mais victimas produziu. Debaixo de uma zona como a que
estamos, como um ar impregnado de humidade e onde a vida dos vegetaes é um de
uma exuberância indescriptivel, é natural que o impaludismo endemicamente viva
comnosco nas mais vantajosas condições. Em outros anos, durante a época menos
chuvosa, temos sido acometidos de fébres palustres epidemicamente tomando caracter

\footnotetext{
${ }^{3} \mathrm{O}$ conceito de Belle Époque cristalizado pela historiografia celebrativa amazonense diz respeito a um momento histórico (que se iniciam em 1890 e finda nas primeiras décadas do século XX) em que as elites locais buscavam seguir uma mentalidade burguesa e ostentavam as benesses dos melhoramentos urbanos realizados na área central de Manaus patrocinados pela economia da borracha. Ver mais em DIAS, 1999.
} 
assustador; o anno último, porém, esta capital não experimentou os efeitos da epidemia paludica. (PEREIRA, 1897, p. 94).

Percebemos que os elementos da natureza amazônica como a alta umidade, a quantidade de vegetais e o regime das águas contribuíram para a incidência da doença. Nesse sentido, podemos observar as influências ainda presentes da teoria miasmática no entendimento sobre a malária.

Com o passar dos anos, a teoria do mosquito-vetor foi adentrando no saber médico local e a partir de então podemos observar uma certa mudança na interpretação sobre a malária com acolhida da ideia do mosquito Anopheles, enquanto transmissor da doença entre os médicossanitaristas amazonenses. Isso não implicou no desgaste da teoria miasmática de modo total, embora tenha havido uma mescla de interpretações sobre a malária e em alguns casos uma rivalidade aberta entre os médicos amazonenses no tocante à etiologia da doença.

Desse modo, nosso artigo parte da hipótese de que houve mudanças na interpretação e diagnóstico da doença, que ocorreu em parte devido ao decreto que criou o primeiro Regulamento Sanitário Republicano em Manaus. Acreditamos que esse órgão, embora estivesse subordinado a Junta de Higiene, passou a tratar dos assuntos sanitários com um viés científico, mais preocupado com as questões de higiene e salubridade se comparados a época provincial.

Além disso, observa-se o intenso trânsito de informações que os médicos amazonenses absorvem no contexto em que a cidade de Manaus passa pelo seu primeiro surto de urbanização no final do século XIX, assim como a formação das primeiras comissões de saneamento de Manaus compostas por médicos-sanitaristas. Esses novos conhecimentos e as mudanças na fisionomia da cidade provocam novos debates sobre a malária, sobretudo entre 1898 e 1904. Ao mesmo tempo, suscitam a chegada de novos paradigmas, como o do mosquito-vetor que passarão a ser debatidos entre os médicos locais, sem desconsiderar as ideias já existentes conforme veremos adiante.

\section{A MALÁRIA NA CIDADE DA BORRACHA: TRANSFORMAÇÕES URBANAS E DEBATES MÉDICOS}

Os últimos anos do século XIX foram intensos em Manaus. A produção da borracha natural em larga escala e o consequentemente escoamento do produto atendendo as necessidades do capital estrangeiro permitiram um acúmulo de capital jamais visto. Rapidamente, a cidade atraiu pessoas de diferentes localidades, desde estrangeiros e nacionais que vieram fazer negócios e em alguns casos fixar residência. Os administradores locais aproveitaram o excedente comercial e tornaram a cidade um verdadeiro canteiro de obras. A historiadora Maria Luiza Ugarte Pinheiro (2015) disserta que nesse momento houve a:

\footnotetext{
Renovação dos prédios públicos, as construções monumentais, os aterros e desaterros, a abertura de ruas e avenidas foram acompanhadas pela incorporação, em alguns casos pioneiros, de tecnologias urbanas modernas como o sistema de bondes, a iluminação elétrica, sistema de galerias para drenagem de água e esgoto, além da abertura de espaços destinados ao lazer refinado, hipódromo, teatro, clubes, etc. (PINHEIRO, 2015, p. 41-42).
}

Ao mesmo tempo em que a cidade se transformava do ponto de vista estético, algumas velhas conhecidas marcavam sua presença no instante em que se efetuavam as reformas urbanas. Falamos aqui da malária que alcança notoriedade devido a três epidemias sucessivas. Primeiro em 1897, a doença atinge 1.074 óbitos, posteriormente em 1899 morrem 710 e por último em 1900, 1.495 vidas são ceifadas naquela que foi a maior epidemia da história de Manaus no século XX conforme Júlio Silva (2012). 
Não obstante, as autoridades governamentais e médicos-sanitaristas começaram a fornecer suas explicações para o elevado número de óbitos. Um deles foi o médico Hermenegildo Campos, que fez o seguinte comentário:

\footnotetext{
Nesses anos (1897 a 1898) as excavações tornaram-se um delírio; eram feitas em todos os lugares e ao mesmo tempo cavava-se, aterrava-se depois lugares excavados; recavava o mesmo lugar, etc. Tal movimento de terras, concorreu muito para a recrudescência das febres. Aterraram-se igarapés, deixando-se grande espaço entre os dois aterros, ficando pântanos artificiaes dentro da cidade. (CAMPOS, 1988, p. 6566).
}

Observa-se na fala do médico a crítica em relação a intervenção no espaço urbano, pois "cavava-se e recavava o mesmo lugar". Segundo Hermenegildo Campos, o movimento de terras ocorrido em grande medida para aterrar igarapés não levaram em conta os riscos de se produzirem os pântanos artificiais, e, portanto, as febres (leia-se malária) voltaram a ser uma realidade na cidade, pois disseminavam os miasmas no ambiente. Em outras palavras, ao mesmo tempo em que as obras buscavam embelezar a urbes, não consideravam os riscos contra a salubridade da cidade. Nota-se o primeiro embate entre o projeto de cidade que se pretendia construir e os sanitaristas.

Os debates sobre as doenças foram fruto de um momento importante do ponto de vista sanitário em Manaus. Segundo Júlio Schweickardt (2009), os primeiros anos da República em Manaus assistiram à formação de diferentes comissões de saúde pública e tiveram como objetivo o estudo e a formação de medidas de saneamento na cidade e, posteriormente, a organização de profilaxias específicas para o combate das doenças tropicais - a exemplo da febre amarela e malária. Esse movimento foi um reflexo de um evento anterior, a criação do Primeiro Regulamento do Serviço Sanitário de Manaus em 1891 na gestão do então governador Guilherme de José Moreira. Para Silva Filho (2013), o Serviço Sanitário estava subordinado a uma Inspetoria de Higiene que a partir daquele momento seria responsável pela administração pública dos assuntos relacionados às condições de salubridade da capital e dos municípios amazonenses, muito embora apenas Manaus tenha sido objeto de trabalho do referido órgão.

Acreditamos que esse duplo movimento contribuiu para intensificar o debate em relação às doenças na cidade. Ressalte-se que as discussões sobre as doenças não eram necessidade nova, pois durante a Província do Amazonas, os médicos e os presidentes de Província (O equivalente aos governantes na República), conservavam no tocante ao debate as influências da teoria miasmática e da climatologia médica sobre interpretação da malária. A climatologia médica é um campo do conhecimento científico que leva em conta as características ambientais e humanas de uma determinada região, como possíveis responsáveis pelo aparecimento de uma doença. Segundo Flávio Edler (2003), um dos fatores que refletiam nesse processo, seriam os circunfusa, ou seja, as questões relativas ao clima, a geologia e hidrologia de um referido lugar.

Observamos essa assertiva ao examinar os relatórios da Junta de Higiene de 1898:

Procurando o factor que tem motivado o aumento das febres palustres, julgamos não ser contrariados incriminando como causa determinante o começo da vasante do Rio Negro. Bem sabemos que a proporção que o volume das aguas diminue, vae ficando descoberto nas margens do rio citado e dos igarapés existente na cidade e circunvisinhança. Em vários logares dos igarapés da Cachoeirinha, Cachoeira Grande, Castelhana, Manaós e Bittencourt etc., os raios de sol não penetram até a superfície do solo em virtude dos diagramas neles existentes, constituídos pelas grandes árvores, não só em suas margens como nos próprios leitos: dahi a resultante assaz desfavorável da existência de uma atmosfera pesada, excessivamente viciada, contendo em si todos os miasmas, todos os princípios deletérios possíveis (MATTA; PALHANO, 1898, p. 73). 
É perceptível como o discurso dos médicos sobre a doença vai se modificando a partir da aparição de novos elementos. Se antes as ações humanas eram as responsáveis pelo aumento das febres, temos agora o fenômeno da vazante do Rio Negro, que alimenta os igarapés que entrecortam a cidade, como amplificador do processo. Segundo Cristiana Grobe (2014), os igarapés eram comumente depreciados no discurso dos médicos e governantes, uma vez que eram vistos como obstáculos ao crescimento e desenvolvimento urbano, além de serem elementos possuidores e proliferadores de doenças.

Outro médico que na época deu sua contribuição para o debate foi o Dr. Carlos Grey. Ele afirmava que "as causas geradoras residem na grande quantidade de águas que nos vem das chuvas e da cheia do rio e dos igarapés" (GREY, 1899, p. 74). Todavia, o discurso do médico ressalta também que:

As primeiras encontrando as nossas ruas descalçadas, constantemente revolvidas, como que para buscar novas camadas de germens para a superfície, cheias de imensos buracos, aterros feitos sem ordem nem providencia por toda a cidade de modo a impedirem o naturalmente escoamento das aguas, formam ali e acolá pequenos e grandes pântanos artificiais que infeccionam todo o ambiente e só tendem a desaparecer com a grande secca da estação futura; as segundas sem a canalização regular que lhes tolha o passo, invadem os terrenos marginaes, alagam-nos e vem por idêntico processo ao das chuvas constituir outros tantos pântanos.' (Ibid.)

Vale ressaltar que Carlos Grey ainda faz sugestões para a melhoria da salubridade do instituto e da cidade a partir de experiências realizadas em outras partes do país, a seguir exposto:

Eu o aconselharia seguir um plano methodico de arruamento, calçamento e dreinagem da cidade e a modificação completa do abastecimento d'agua, não só a relação a quantidade como a qualidade: para este segundo ponto nos lembraríamos imitar a cidade de Campos (no Rio de Janeiro), que como se base está situada quase na foz do Rio Parahyba, depois de extensissimo percurso pelos Estados de S. Paulo e Rio de Janeiro. Pois bem, Campos é abastecido pela água do Parahyba que se torna boa qualidade depois da filtração e purificação para ser lançada nas bombas no encanamento geral $[\ldots]$ (Ibid.)

A sugestão feita pelo médico em relação ao abastecimento da água mostra que havia circulação de ideias entre os médicos em nível nacional com o local, isto a partir dos exemplos de ações realizadas em outros estados brasileiros. No que diz respeito ao plano de arruamento, percebemos que o modelo descrito pelo médico para o Instituto apresenta características mais específicas:

Nós indicaremos o nivelamento e calçamento das ruas e cercanias do Instituto de modo a terminar com os charcos existentes alli mesmo junto d'elle e do projectado palácio do governo; rever o nivelamento do próprio terreno do Instituto, examinar o estado do igarapé dos fundos na Rua Leonardo Malcher, dando escoamento as suas aguas, se necessário for. (Id. , pp. 74-75).

Podemos observar mais uma vez o intuito de modificar os elementos que faziam parte da paisagem urbana a partir de nivelamentos dos terrenos, isto com o objetivo hidráulico, ou seja, sem permitir acúmulo de água estagnada. Desse modo, o discurso dos médicos-sanitaristas não se punha necessariamente contra os aterramentos, mas sim ao modo de como eles eram realizados.

Essa questão se manteria na pauta de discussão e estaria longe de ser consenso a partir dos primeiros anos do século XX. Em 1900, a família dos Nery assume o poder na cidade e o governador Silvério Nery se posiciona na sessão "Hygiene Pública" nos seguintes termos: 


\begin{abstract}
O saneamento desta cidade, como a de todo o globo, implica imediatamente a purificação de duas zonas distinctas: o ambiente e o sub-solo. $\mathrm{O}$ ambiente porque leva a economia organica dos habitantes todos os germens tóxicos que contém o sub-solo, porque delle pela evaporação emanam miasmas, que são absolvidos e pela infiltração envenenam o lençol d'agua subjacente que, uma vez utilisado, se torna grandemente nocivo a saude pública. Para intoxicação do ambiente contribuem fatores accidentaes e estes factores estiveram aggindo a pouco intensamente [...] taes foram as multiplas excavações no solo, comprehendendo extentíssimas areas e feitas a modo de repellir a todo critério [...] a consequencia imediata dessa cegueira em matéria de saúde pública, deu-se a mais tremenda propagação da toxina do impaludismo. Ainda encontrei infelizmente excavações, ao assumir a administração, e um dos meus primeiros actos foi manda-las sustar de prompto. $\mathrm{O}$ impaludismo que tomara caracter epidemico, cedeu então. (NERY, 1901, pp. 11-12). Grifos nosso.
\end{abstract}

Vemos aqui a combinação de dois elementos que justificam a presença da malária na cidade: o ambiente e o subsolo, pois ambos têm potencial para produzir os germes causadores da doença. Todavia, as escavações realizadas também contribuem para o processo. Em outros termos, os aterros e desaterros de igarapés, o que nos lembra o discurso de parte dos sanitaristas em relação aos riscos dos movimentos de terras conforme Silva Filho (2013).

É válido ainda destacar a ausência do termo "febres" na fala do governador, embora haja elementos da climatologia médica a exemplo do papel do meio ambiente e da teoria miasmática em seu entendimento, bem como os pressupostos da teoria do solo de Max von Pettenkoffer, algo que ressalta o papel das condições climáticas para a ativação do germe no ambiente segundo (BENCHIMOL, 2001).

A preocupação do governador em suspender as obras se deve pelo fato da moléstia ter alcançado em 1900 a cifra de 1.495 óbitos, e constitui-se na maior epidemia registrada da doença, superando as 1.074 vítimas de 1898 (SILVA, 2012). Acreditamos que as duas epidemias, num intervalo de três anos, contribuíram para modificar as ações dos agentes públicos em relação à doença, materializadas na paragem das obras de terraplanagem.

Todavia, essas ações ainda não são suficientes para alterar o entendimento em relação às causas da doença. Em relatório anexo à mensagem, o chefe da Diretoria de Higiene Pública, Dr. Alfredo da Matta (1901), utiliza-se do argumento da autoridade quando se posiciona em relação às modalidades de malária.

O mestre dos mestres, sobre o assumpto, Laveran, que tem estudado com abnegação
cientifica o paludismo com todas as suas evoluções e modalidades, declara que a terra
é indispensável a propagação do paludismo, declarando que a influencia do solo é
tornada manifesta e que os trabalhos de subbida e terraplanagem são particularmente
perigosos nos paizes palustres; estes trabalhos podem mesmo dar logar a epidemias
de febres palustres fora dos focos epidêmicos. (MATTA, 1901, p. 6-7).

Alphonse Laveran foi médico-militar e cirurgião francês e responsável por identificar no sangue de doentes de Malária, ou seja, o protozoário Plasmodium em seu primeiro estágio de reprodução em 1880 (SCHWEICKARDT, 2009). No entanto, Alfredo da Matta não faz nenhuma menção a esse fato, embora reconheça a importância do solo na propagação da doença, conforme apontado pelo médico-cirurgião francês.

Outro elemento que o médico considera relevante nesse assunto é o papel da água para a propagação da doença, assim descrita:

Si folhearmos o trabalho de Laveran sobre a água veremos que ele cita de Raymond que diz os habitantes de Landes Bordelezas e de muitos pontos do departamento de Gironde, bebem a água pantanosa: ora aqueles que filtram essa agua em filtros de carvão não contraem a febre palustre. Substitua-se as palavras Landes Bordelezas por Manaós e Gironde por Amazonas e essa directoria declara corretamente que taes 
proposições nos são aplicáveis de modo exacto, pois, é por demais importante o papel da água sobre a pathogenia do paludismo. (Id., p. 15)

Nesse momento são tomados como modelos o fornecimento da água em diferentes regiões da França e sua relação com o aparecimento da doença, muito embora o médico reconheça os limites dessa comparação. Desse modo, podemos afirmar que os elementos da climatologia, como o papel da água se constituía naquele momento como obstáculo epistemológico para aceitação total da ideia do mosquito Anopheles enquanto transmissor da malária entre os higienistas amazonenses, embora a menção aos trabalhos de Laveran representasse um primeiro sintoma numa possível mudança de abordagem nos anos seguintes.

No ano seguinte, a Mensagem de governo de 1902 confirma a queda no número de óbitos por malária em Manaus. Enquanto em 1900 houve 1495 mortes por malária, em 1901, a cifra caiu para 614 vítimas (SILVA, 2012). Segundo o governador Silvério Nery as razões disso se devem a paralisação dos serviços de terraplanagem:

Tenho por seguro que a paralysação quase completa de movimentos de terras, que tanto concorreu, para o poussées de febres de tempos que não vão longe, é o principal factor d'esse descrescimento de porcentagem, descrescimo que ainda será maior se, a respeito de todos os casos, os diagnósticos tiveram por base o exame seguro, o único possível de bacteriologia. (NERY, 1902, p.12).

É interessante notar que a diminuição dos serviços de modificação do solo contribuiu para o decréscimo das febres na cidade. Citamos também a solicitação por um diagnóstico mais preciso sobre os casos registrados, seguindo os parâmetros da bacteriologia, ramo da ciência que estava se impondo naquele momento. Em seguida, o governador chega a questionar a classificação da moléstia. Para ele:

\footnotetext{
Se acobertam apreciações incompletas ou casos de fundo desconhecido ou deturpado, como aconteceu com as próprias grandes febres que se manifestam simultaneamente com a pyrexia das excavações, nem todas talvez de natureza realmente paludosas e com o aparecimento de cólicas biliares e estados semelhantes, de origem desconhecida e, pela facilidade também, a conta do impaludismo postas. (Ibid.)
}

Conforme comentamos anteriormente ainda não havia um diagnóstico preciso sobre a doença, havendo, portanto, a possibilidade de surgirem morbidades de origem desconhecida ou então, a confusão com outras doenças de sintomas parecidos como a febre tifóide no caso das febres paulistas; o que levava as autoridades a duvidarem dos diagnósticos realizados (TEIXEIRA, 2004).

Era comum nos atestados de óbito os médicos declararem que a causa da morte fosse impaludismo, não podendo saber que variedade da doença havia se manifestado (CAMPOS, 1988). Desse modo, havia uma classificação aproximada da causa do óbito que considera as consultas feitas pelos mais antigos clínicos da cidade, ou seja, aqueles que se ocupavam com a doença. A identificação do Anopheles enquanto transmissor da doença no fim do século XIX viria a trazer um novo e importante elemento no debate sobre a malária nos anos subsequentes.

\section{ENFIM, O ANOPHELES. MAS NÃO APENAS ELE}

A primeira experiência que identificou o Anopheles enquanto transmissor da malária em humanos foi realizada em 1899 pelos médicos italianos Amigo Bignani, Giovanni Grassi e Giuseppe Bastinelli (SCHWEICKARDT, 2009). Utilizando voluntários humanos como cobaias previamente picados por mosquitos infectados, percebeu-se que a malária poderia se desenvolver nos seres humanos com a picada do mosquito. A partir de então, se configurou a 
teoria do mosquito-vetor dentro do meio científico e ela não tardou a estimular debates devido às novas perspectivas sobre as doenças tropicais, após a percepção do mosquito como transmissor da febre amarela e da malária em Cuba, observado pela comissão estadunidense chefiada por Reed e Carroll, e na Itália por Grassi, respectivamente (SCHWEICKARDT, 2009; SILVA FILHO, 2013).

As observações tiveram ressonância na medicina brasileira, onde posteriormente se detectou o Stegomyia fasciata como agente transmissor da febre amarela a partir das experiências realizadas por Emílio Ribas, em São Paulo, e o Anopheles como transmissor da malária a partir dos estudos de Adolpho Lutz nas linhas ferroviárias no vale paulistano (BENCHIMOL, 2005; SILVA FILHO, 2013).

Desse modo, há uma ressignificação no que diz respeito ao entendimento das doenças que antes eram entendidas unicamente sob as bases da teoria miasmática e começam a se misturar como os pressupostos da medicina tropical que traz como fato novo a participação dos parasitas que agem dentro do organismo nos seres humanos e os mosquitos infectados como vetores conforme veremos adiante.

Segundo o médico, Dr. Alfredo da Matta:

\begin{abstract}
Se tem seguido, dia após dia, a evolução do paludismo nos Anopheles que tinham se alimentado de sangue palustre; se tem realizado a inoculação dessa moléstia em indivíduos sãos; fora dos focos de infecção, fazendo-os serem picados pelos Anopheles inficionados. Em todas as zonas palustres a existência desses culicidios tem sido demonstrada e a nossa as possui em abundância; a sua destruição se impõe. Os mosquitos necessitam de água estagnada para sua evolução; é na superfície delas que as gêmeas depositam seus óvulos e em taes águas que as larvas e as nymphas vivem até o momento de sua transformação em insetos perfeitos [...] (MATTA, 1902, p. 65).
\end{abstract}

Com efeito, o Dr. Alfredo da Matta torna-se o primeiro médico amazonense a reconhecer o protagonismo do mosquito Anopheles na transmissão da malária, embora ainda guarde as influências da teoria miasmática ao evidenciar uma possível relação entre a água e sua importância no ciclo de vida do vetor.

Assim, entendemos que houve uma aceitação preliminar em relação aos trabalhos realizados com mosquitos no Brasil e em outras partes do mundo pelos médicos amazonenses. Um exemplo disso é o momento em que o Dr. Alfredo da Matta faz menção ao médico inglês Patrick Manson para atestar sua posição.

Porém, é necessario elucidar que para eles não é desconsiderado o papel da água estagnada na transmissão da doença. Ela passa a ser ressignificada e tornar-se-á importante no que diz respeito ao ciclo de vida e para a evolução do mosquito.

Alfredo da Matta ainda cita medidas de combate ao mosquito inspiradas nas conclusões do médico Hilário de Gouveia. Elas foram trabalhadas na tese de Júlio Schweickardt, mas reproduzimos aqui por considerar sua relevância - sem esquecer do pioneirismo do autor citado - que Alfredo da Matta esclarece-nos da seguinte maneira).

\footnotetext{
A prophylaxia da febre amarela é a mesma do paludismo e da filarioses [...] Para evitar os mosquitos: a) a proteção dos indivíduos sãos pelos mosquiteiros; b) o isolamento do mesmo processo, o único que offerece toda a segurança para preservação das pessoas sãs; c) durante as horas de nocividade desses insetos procurar abrigo nas alturas; d) nos meios perigosos habitar os andares mais elevados das casas e arejá-los largamente; e) cobrir com telas metálicas inacessíveis aos mosquitos os reservatórios d'água, até mesmo os jarros com flores, tanto no interior da habitação, como em suas vizinhanças. (MATTA, 1902, p. 65-66 apud SCHWEICKARDT, 2009, p. 135)
}

A primeira observação diz respeito ao entendimento de que havia a mesma profilaxia 
para três moléstias que tinham o mosquito como vetor. Isso é uma questão importante porque a espécie que transmite a febre amarela não é Anopheles, tampouco é este que transmite a filariose, mas sim o mosquito Culex fatigans; conforme Patrick Manson atestou pela primeira vez em 1877 quando trabalhava na Ásia.

Em suma, é compreensível que haja essa orientação, pois as discussões em torno do mosquito-vetor estavam sendo assimiladas a pouco tempo pelos higienistas locais e havia crença de que combatendo um mosquito, os outros poderiam ser eliminados. De resto, as medidas citadas acima possuem um caráter defensivo, na qual o mosquito independente se estivesse infectado ou não, deveria ser evitado, seja com mosquiteiros, uso de telas metálicas etc.

Essas medidas não são necessariamente novas, pois já vinham sendo aplicadas em outras partes do mundo, como nas colônias da África e Ásia pelas potências coloniais como Alemanha, França e Inglaterra, mas a sua aparição na fala dos higienistas amazonenses constitui-se num fato inédito na documentação.

Desse modo, são sugeridas como medidas para destruir os mosquitos os seguintes procedimentos:

a) empregar contra as larvas substancias reconhecidas como eficazes: alcatrão, petróleo e mesmo sal de cosinha em dose alta (para os pântanos), lembrando-se, porem que o emprego dessas substancias deve ser renovado todas as semanas; b) quando o emprego desses meios é impossível, por haver necessidade da água do reservatório, como bebida para o homem e para os animais, povoar o depósito com peixes nos quais destroem as larvas dos mosquitos ou cobri-los com telas metálicas, de malhas finíssimas; c) drenar e nivelar o solo, evitando a estagnação das águas. (MANSON, 1897 apud SCHWEICKARDT, 2009, p. 80)

O foco principal nas medidas de ataque é justamente eliminar as larvas, segundo estágio no ciclo de vida do Anopheles. O objetivo seria interromper a cadeia de transmissão homemmosquito antes do último chegar a sua fase adulta. Desse modo, podemos considerar o programa apresentado por Alfredo da Matta como híbrido, pois apresenta uma mescla de ações verticais e horizontais, uma vez que buscam agir de forma autoritária sobre a paisagem, principalmente os igarapés e ao mesmo tempo consideram seus aspectos sociais numa perspectiva mais ampla. Dessa forma, podemos perceber a importância social da doença e do mosquito Anopheles como atores sociais, sendo igualmente fatores numa possível configuração e estruturação das estruturas sociais na urbe.

Obviamente, não podemos perder de vista os interesses políticos e sociais em torno dessas ações. Nesse sentido, convém retomarmos as lições de Sidney Chalhoub a respeito do assunto, para ele na corte imperial buscou-se gerir a cidade e a política de acordo com critérios puramente técnicos, de modo a escamotear a intencionalidade dos atores sociais presentes no pensar dessas intervenções que visavam combater a febre amarela naquele momento (CHALHOUB, 1996). Argumentamos que os médicos-sanitaristas amazonenses se valeram de um discurso científico e da profilaxia de combate à malária para impor a sua visão de cidade saneada e livre das doenças naquele momento.

Conforme vamos avançando da documentação percebemos que a doença continuaria a ser uma presença constante no discurso dos agentes do Estado nos anos seguintes. Segundo Alfredo da Matta em Relatório (1903, p. 35) “ A malária voltaria a registrar o aumento em número de óbitos com 776 vítimas, representando 49,9\% sobre a mortalidade geral”. O médico não faz menção a razão do aumento de casos, todavia disserta sobre as principais modalidades da doença que são "febre intermitente, febre remitente simples ou complicada; manifestações larvadas; cachexia palustre, além da intercurrência do impaludismo em outras moléstias" (Id., p. 43).

Esse último ponto é importante, pois segundo Alfredo da Matta seria difícil sem o 
auxílio do microscópio diferenciar a moléstia da tuberculose, outra doença que existia também em Manaus.

A fim de asseverar tal interpretação, o médico recorre novamente às referências estrangeiras, demonstrando seu conhecimento acerca das experiências médicas em nível internacional. Segundo ele:

O que tanto nos impressiona, aqui no norte, taes as lesões que o impaludismo determina em duas importantes vísceras, o baço e o fígado, tem perdido quase a sua importância clássica perante a cabal experiência e peremptória demonstração que a phymatose as produz também, como declaram Widal, Collet, Rendu e Gallavardin. Podem ser hepatites tuberculosas, esplenomegalia [...] Não estamos, é bem verdade, compreendidos na conclusão de Bernheim, na ação predisponente do impaludado para nelle manifestar a phymatose. Jeannonpoulos tira também a mesma conclusão, isto é, que os tuberculosos da Ásia Menor são aptos a se impaludar e vice- versa. (MATTA, 1903, p. 43).

Assim, entendemos a importância do microscópio para o médico, pois com o uso desse instrumento seria possível diferenciar a malária de quaisquer outras doenças. O problema do diagnóstico é entendido como de suma importância. Pois implicaria na possibilidade de uma melhor compreensão sobre a etiologia da doença que comumente confundia os médicos locais devido aos seus sintomas.

Para tanto, em 1904, o governador Constantino Nery criou a Comissão de Saneamento de Manaus. O objetivo dela seria estudar as condições do clima e natureza do solo amazônico, de modo a propor medidas sanitárias que pudessem amenizar os impactos das doenças sobre a população local, dentre elas a malária (SCHWEICKARDT, 2009).

Por conseguinte, o governador nomeou seu irmão, Dr. Márcio Nery como chefe da referida comissão. Não pretendemos aqui falar dela e de sua composição ${ }^{4}$, mas sim verificar os pontos que Márcio Nery considerou relevantes na discussão e entendimento do problema da malária em Manaus.

Ao lado do homem, há uma flora microbiana e uma fauna de animalculação nocivas e parasitas, que tiram benefício da temperatura e da humidade e de climas intertropicais com o nosso. Muitos encontram o seu meio optimo e desenvolvem-se com exuberância, constituindo-se como uma ameaça aos habitantes desse clima [...] Todas as vezes que a temperatura se aproxima do corpo humano, esses seres extremamente pequenos, adquirem uma recrudescência de sua virulência, tornandose extremamente perigosas para o homem. Em Manaós, encontram-se uma variedade uma rica variedade de mosquitos, muitos dos quais se prestam a vehiculação de agentes pathogenicos. (NÉRY, 1905, p. 122-123).

Para o chefe da comissão de saneamento, o clima tropical de Manaus contribuía para a criação de condições que aumentassem a virulência dos mosquitos, reconhecidos transmissores de doenças sob a população local. Além disso, as variáveis climáticas e a rica fauna de insetos transmissores poderiam amplificar o processo, agindo também outros fatores, como:

[...] em muitas ruas em que os aterros não concluídos deixam covões, nas depressões das próprias ruas, nas margens dos igarapés de águas pouco correntes [...] a água da chuva colecionando-se, pode tornar-se e efetivamente se torna viveiros de mosquitos de todas as espécies [...] (Id., p. 124)

\footnotetext{
${ }^{4}$ O historiador Júlio César Schweickardt fala sobre a constituição da Comissão de Saneamento de Manaós no capítulo 3 de sua tese. Ver tópico 3.3: A comissão de saneamento em Manaus (1904-1906). (SCHWEICKARDT, 2009, pp. 150-184).
} 
Nesse momento, o dr. Márcio Nery ressalta a mesma crítica em relação aos aterros realizada por muitos sanitaristas já citados, e segue então a mesma linha adotada por Alfredo da Matta. Uma das características da comissão é a utilização de pesquisas sobre os mosquitos, no qual são assinalados os seus locais de procriação e a parte do ano em sua aparição é mais constante na cidade de Manaus.

Nesse sentido, o dr. Márcio Nery comenta que:

\begin{abstract}
As águas da bacia do Rio Negro sobem em regra geral a começar na segunda quinzena do mês de dezembro. Coincide, de ordinário, essa enchente com o período das chuvas [...] as águas paradas ou lentamente correntes, oferecem um meio favorável para o desenvolvimento de toda uma fauna de culicidios que em nuvens se levanta da agua desde que o voulo sofreu a sua metamorfose. Foi o que observou esse ano no Igarapé da Cachoeirinha, no Igarapé do Bittencourt e no Igarapé de Manaós. Os Anopheles, que até então, dificilmente se encontravam, começaram a aparecer dentro dos domicílios. Em Junho, começa a vazante dos rios que constituem a bacia do Rio Negro. Em muitos pontos ficam aguas estagnadas, que pouco a pouco, se evaporam sob a influência do sol na estação secca. Até certo ponto, repetem-se os mesmos fenômenos que se observam no princípio das enchentes. (SCHWEICKARDT, 2009, p. 177)
\end{abstract}

Para o médico, o regime das águas também apresenta sua parcela de responsabilidade, pois cria condições favoráveis para a proliferação dos mosquitos; seja durante o período de chuvas no início do ano, seja na vazante. Nessa condição, a quantidade de mosquitos na cidade era renovada mais facilmente, contribuindo para a permanência da malária em Manaus durante todo o ano.

\title{
3 CONSIDERAÇÕES FINAIS
}

A história da malária, no alvorecer da República em Manaus, apresentou idas e vindas e esteve longe de promover um consenso no discurso de governantes e médicos-sanitaristas acerca da sua etiologia e transmissão na capital da Borracha. Para desenvolver nossa investigação nos valemos da análise do discurso a fim de compreender as perspectivas sobre a malária nos relatórios médicos e nas mensagens de governo. Identificamos que a narrativa sobre as influências dos miasmas estavam presentes desde o ínicio na documentação analisada. Embora tais debates remontam aos últimos anos da época provinciana, verifica-se a importância da água e do ar para o desencadeamento das febres, ou seja, podemos dizer que houve uma certa mudança em seu entendimento à medida que entramos no século XX.

Podemos observar que os elementos da paisagem urbana da cidade como a vegetação e os igarapés também eram responsabilizados por liberarem os miasmas no ambiente. Além disso, as ações humanas como as escavações e aterros em áreas previamente alagadas também foram compreendidas em grande medida pelos médicos-sanitaristas e governadores responsáveis por desencadear as febres em Manaus.

Por fim, a acolhida da teoria do mosquito representou mais um elemento no debate sobre a malária à medida que o Anopheles passou a ser identificado como mosquito transmissor da doença. $\mathrm{O}$ fato não implicou necessariamente o desgaste total das teorias dos miasmas, pois como vimos, os aterros e os igarapés continuaram a ser espaços vistos como potenciais criadouros de mosquitos, formalizando uma interpretação híbrida sobre a doença. Em síntese, os debates sobre a malária acompanharam as transformações urbanísticas de Manaus, na virada do século XIX para o século XX, e como vimos mesmo após a acolhida de uma nova teoria continuou orbitando entre miasmas e Anopheles.

\section{REFERÊNCIAS}


BENCHIMOL, Jaime Larry (Coord.). Febre Amarela: a doença e a vacina, uma história inacabada. Rio de Janeiro: Editora Fiocruz, 2001.

BENCHIMOL, Jaime Larry (Org.). Febre Amarela, malária e protozoologia. Rio de Janeiro: Editora Fiocruz, 2005 (Adolpho Lutz Obra completa, v.2, Livro 1).

CAMPOS, Hermenegildo Lopes de. Climatologia Médica do Estado do Amazonas. Manaus: ACA/Fundo Editorial, 1988.

CHALHOUB, Sidney. Cidade Febril: Cortiços e epidemias na Corte Imperial. São Paulo: Companhia das Letras, 1996.

COSTA, Cybele. Socorros públicos: as bases da Saúde Pública na Província do Amazonas.2008. Dissertação (Mestrado em História) - Universidade Federal do Amazonas, UFAM, Manaus, 2008.

DIAS, Edinea. A ilusão do fausto: Manaus, 1890-1920. $2^{\text {a }}$ ed. Manaus: Valer, 1999.

EDLER, Flávio. A medicina no Brasil Imperial: fundamentos da autoridade profissional e da legitimidade científica. Anuário de Estudos Americanos. Tomo LX, I, 2003. Disponível em: http://arca.fiocruz.br/handle/icict/26106. Acesso em: 14 maio 2021.

GREY, Carlos. Relatório médico apresentado ao Ill.mo e Exc.mo Sr. Coronel Pedro Freire, dignissimo Secretário dos Negócios do Interior do Estado do Amazonas. Manaus: Tipographia Amazonas, 1899.

GROBE, Cristiana Maria Petersen. Manaus e seus igarapés: A construção da cidade e suas representações (1880-1915). 2014. Dissertação (Mestrado em História) - Universidade Federal do Amazonas, UFAM, Manaus, 2014.

MATTA, Alfredo Augusto da; PALHANO, Antonio de Carvalho. Relatório apresentado Sr. Chefe do Departamento do Interior Justiniano de Serpa. In: FERREIRA, Fileto Pires.

Relatório apresentado pelo Secretário de Negócios do Interior em 5 de janeiro de 1898. Manaós: Typographia de F. De Queiroz \& Comp., 1898.

MATTA, Alfredo Augusto da. Oficio da Diretoria Geral de Higiene Pública do Estado do Amazonas. Dirigido ao Governador Silvério Nery. NÉRY, Silvério José. Mensagem lida perante o Congresso do Amazonas em 19 de junho de 1901. Manaus: Tipografia Ferreira Pena, 1901.

MATTA, Alfredo Augusto da. Relatório da Diretoria Geral de Higiene Pública do Estado do Amazonas. Dirigido ao governador Silvério Nery. NÉRY, Silvério José. Mensagem lida perante o Congresso do Amazonas em 10 de julho de 1902. Manaus: Tipografia Ferreira Pena, 1902.

MATTA, Alfredo Augusto da. Relatório da Diretoria Geral de Higiene Pública do Estado do Amazonas. Dirigido ao governador Silvério Nery. NÉRY, Silvério José. Mensagem lida perante o Congresso do Amazonas em 10 de julho de 1903. Manaus: Tipografia Ferreira Pena, 1903. 
NÉRY, Silvério José. Mensagem lida perante o Congresso dos representantes, por ocasião da abertura da primeira sessão da quarta legislatura de 10 de julho de 1901 pelo Dr. José Silvério Nery, governador do Estado. Manaus: Tipografia Ferreira Pena, 1901.

NÉRY, Silvério José. Mensagem lida perante o Congresso dos representantes em 10 de julho de 1902 pelo Dr. José Silvério Nery, governador do Estado. Manaus: Tipografia Ferreira Pena, 1902.

NÉRY, Márcio. O Saneamento em Manaós. In: NÉRY, Constantino Antonio. Mensagem lida perante o Congresso do Amazonas em 10 de julho de 1905. Manaus: Tipografia Ferreira Pena, 1905.

PEREIRA, Henrique Alvares. Relatório apresentado pelo inspetor de Higiene Pública de Manaós em 20 de janeiro de 1987. In: FERREIRA, Fileto Pires. Relatório apresentado ao governador do Estado pelo Chefe do Departamento do Interior. Manaós: Typographia de F. De Queiroz \& Comp., 1897.

PINHEIRO, Maria Luiza Ugarte. A cidade sobre os ombros: trabalho e conflito no porto de Manaus (1899-1925). $3^{\text {a }}$ Ed. Manaus: EDUA, 2015.

SCHWEICKARDT, Júlio. Ciência, nação e região: as doenças tropicais e o saneamento no Amazonas (1890-1930). 2009. Tese (Doutorado em História das Ciências e da Saúde) - Casa de Oswaldo Cruz/FIOCRUZ, Rio de Janeiro, 2009.

SILVA, Júlio. Adoecendo na cidade da borracha: Manaus (1877-1920). Dissertação (Mestrado em História) - Universidade Federal do Amazonas, UFAM, Manaus, 2012.

SILVA FILHO, Sebastião. A organização do serviço sanitário em Manaus: sanitaristas e suas práticas de intervenção. (1891-1920). 2013. Dissertação (Mestrado em História) Universidade Federal do Amazonas, UFAM, Manaus, 2013.

TEIXEIRA, Luiz Antônio. As febres paulistas na Sociedade de Medicina e Cirurgia de São Paulo: Uma controvérsia entre porta-vozes de diferentes saberes. História, Ciências, Saúde Manguinhos, Vol. 11 (Suplemento 1), 2004. Disponível em:

https://www.scielo.br/pdf/hcsm/v11s1/02.pdf. Acesso em: 14 maio 2021. 